\title{
Análise do impacto nos custos de transporte de um modelo de seleção de fornecedores baseado em variáveis socioambientais e de competitividade
}

\author{
Breno Barros Telles do Carmo ${ }^{\mathrm{a}, *}$, Julio Francisco Barros Neto ${ }^{\mathrm{b}}$, \\ Nadja Glheuca da Silva Dutra ${ }^{\mathrm{c}}$ \\ a,*brenobarros@ufersa.edu.br, UFERSA, Brasil \\ bjfbarros@ufc.br, UFC, Brasil \\ 'nadja@det.ufc.br, UFC, Brasil
}

\begin{abstract}
Resumo
Observa-se uma demanda mundial crescente por energias ditas renováveis. Dentre essas energias, encontra-se o biodiesel, derivado de biomassa renovável. Porém, para que essa cadeia seja competitiva, deve satisfazer alguns critérios de competitividade. Existe também a possibilidade de exportação desse combustível, porém é necessário seguirem-se algumas diretrizes que estão sendo elaboradas para certificação da cadeia de valor dos biocombustíveis, baseada em critérios de sustentabilidade. Assim, o presente artigo tem por objetivo apresentar um modelo de seleção de fornecedores para as usinas de biodiesel, levando em consideração os critérios de certificação e competitividade identificados na cadeia. Foi utilizada a metodologia Smarter para a realização desse modelo. Ele foi agregado em conjunto com um modelo de otimização de transporte para a minimização dos custos envolvidos. Observou-se que o modelo apresenta aumento no custo de transporte, se forem levadas em consideração as imposições de selo social do governo federal.
\end{abstract}

Palavras-chave

Biodiesel. Modelo de seleção de fornecedores. Competitividade. Sustentabilidade.

\section{Introdução}

Observa-se atualmente uma preocupação mundial na produção e consumo de energias mais limpas. Isso vale para a produção e consumo de combustíveis como o diesel. Para a substituição desse tipo de combustível, surgiu o biodiesel, produzido por intermédio de óleos vegetais, sebo bovino ou ainda óleos de gorduras residuais, o que lhe confere um caráter renovável.

Para que essas energias, ditas renováveis, se tornem viáveis, é necessário que elas e o seu processo de produção sejam sustentáveis do ponto de vista socioeconômico e competitivas no mercado globalizado. 0 biodiesel tem grande potencial para atender aos requisitos socioeconômicos, porém, levando em consideração o atual modelo de organização de agricultura familiar, pode representar um custo financeiro mais elevado que o do diesel fóssil. Esse potencial se dá pela inserção da agricultura familiar (AF) nessa cadeia, um dos requisitos impostos pelo mercado globalizado.

Pelo que foi exposto, surgiu o problema a ser trabalhado pelo presente artigo: "como as usinas podem selecionar seus fornecedores segundo critérios socioambientais e de competitividade e qual o custo envolvido no transporte desta matéria-prima?"

Logo, objetiva-se a elaboração de um modelo para avaliar os fornecedores de matéria-prima (MP) para a cadeia produtiva do biodiesel segundo critérios de sustentabilidade e competitividade identificados pelo mundo. Outro fator que será levado em consideração é que o custo de transporte de matéria-prima para as usinas produtoras de biodiesel pode tornar o negócio inviável. Assim, o modelo contemplará também a elaboração de estimativa de custos em função dos fornecedores preferenciais definidos no primeiro modelo. 


\section{Modelo de apoio à decisão}

Chen, Kilgour e Hipel (2009) identificaram que as metodologias MCDA (Multiple Criteria Decision Aid) são a aplicação de variadas técnicas para ajudar na tomada de decisão, ranqueando as melhores alternativas para o problema de decisão.

Definem-se alguns passos básicos dentro de um modelo MCDA (HAMMOND; KENNEY; RAIFFA, 1999; CHEN; KILGOUR; HIPEL, 2009):

- Definir os objetivos de decisão;

- Determinar os atributos (medidas de performance) em consonância com o objetivo proposto;

- Hierarquizar os atributos;

- Determinar os pesos de cada atributo;

- Definir as alternativas candidatas;

- Avaliar as alternativas segundo os pesos adotados; e

- Estabelecer uma fórmula aditiva para obtenção de uma avaliação global.

Grande parte dessas metodologias multicritério passa por essas etapas. 0 que difere é o modelo de atribuição das importâncias e pesos aos atributos.

A Figura 1 ilustra esse processo. Nessa figura, pode-se observar todo o processo de tomada de decisão, em que o decisor avalia as alternativas em função dos critérios de avaliação definidos, chegando as suas consequências, e a preferência é expressa através dos pesos dados aos critérios e valores obtidos pelas alternativas.

Kujawski (2009) entende que existem diversas metodologias MCDA, mas nenhuma pode ser considerada a melhor ou apropriada para todas as situações. Assim, cada situação pode exigir um modelo diferente.

Parreiras (2006) compreende que os problemas de decisão podem ser modelados matematicamente pela maximização de uma função. Com essa função, é possível atribuir uma nota a cada alternativa. A alternativa preferida, nesse caso, é a que obtém a melhor nota em relação às demais. Existem vários métodos que estão contidos dentro dessa linha de pensamento.

Esses métodos são utilizados para definir as importâncias e os pesos de cada um dos critérios e avaliar as alternativas existentes. Em seguida, é necessário elaboração de uma fórmula aditiva que Chen, Kilgour e Hipel (2009) entendem como sendo elaborada seguindo-se três passos básicos:

- Obtenção dos valores das alternativas (níveis de impacto) e os pesos de cada critério;

- Agregação dos valores através dos pesos estabelecidos; e

- Avaliação e ranqueamento das opções disponíveis.

\subsection{Modelo Smarter}

Os modelos Smarts (Simple Multi-Attribute Rating Technique using Swings) e o Smarter foram propostos por Edwards e Barron (1994) para obtenção da utilidade multiatributo. Lopes e Almeida (2008) entendem que esses modelos são simplificações da MAUT (Multi-Attribute Utility Theory), descrita em Keeney e Raiffa (1976), e buscam estabelecer um ordenamento das alternativas.

Cavalcanti (2007) entende que a grande vantagem do modelo Smart está baseada em dois pressupostos:

- A escolha do método deve considerar os trade-off, entre o erros da modelagem e de elicitação;

- Facilidade na implantação do método.

0 Smarts busca corrigir um erro intelectual (preferências dos decisores) do Smart. Lopes e Almeida (2008) entendem que o processo de elicitação de preferências produz erros maiores do que aqueles resultantes das simplificações do modelo; o que justifica a adoção de técnicas mais simples para mensurar a utilidade multiatributo. No Smarter, não há o swing weights. Após a ordenação dos critérios, utilizam-se valores predeterminados denominados ROC weights (Rank Order Centroid

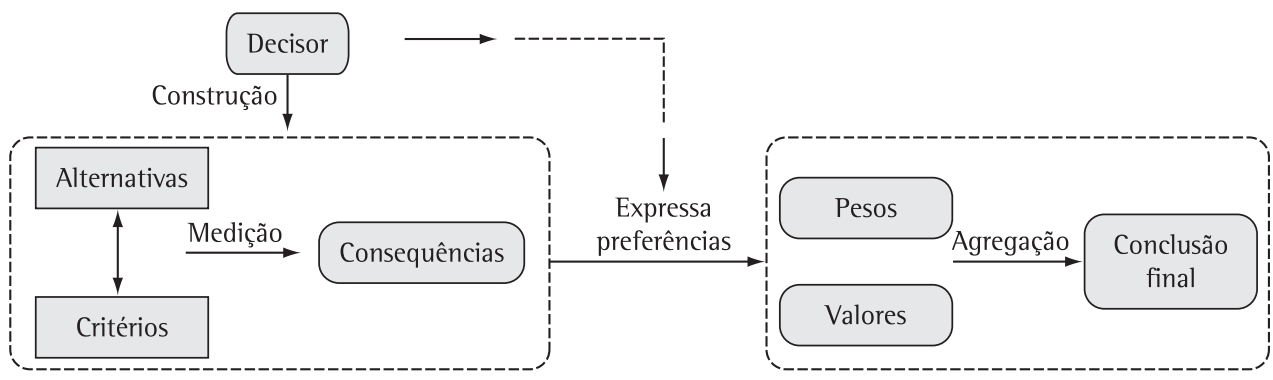

Figura 1. Estrutura de um problema multicritério. Fonte: Chen, Kilgour e Hipel (2009). 
weights) para os pesos, simplificando a obtenção das utilidades multiatributo (LOPES; ALMEIDA, 2008).

Parreiras (2006) entende que existem alguns passos a serem seguidos no modelo Smarter:

- Construção da tabela de avaliação de consequência;

- Eliminação das alternativas dominadas: pequenas variações da variável entre as alternativas implicam em um baixo peso ao critério;

- Transformação dos dados em funções utilidade;

- Agregação dos critérios com uma fórmula aditiva;

- Ordenação dos critérios para a definição dos pesos;

- Cálculo dos pesos através da metodologia ROC; e

- Decisão.

Para cálculo dos pesos, utiliza-se a formulação proposta pela metodologia ROC, ilustrada na Equação abaixo.

$w_{k}=\frac{1}{m} \sum_{i=k}^{m} \frac{1}{i}$

\section{Modelo de otimização linear}

Arenales et al. (2007) entendem que vários problemas reais podem ser estruturados como modelos de otimização linear. Caixeta-Filho (2004) define que modelos são representações idealizadas para situações do mundo real. Dentre esses problemas, observam-se os problemas de transporte, que buscam a identificação das menores distâncias e custos nessa atividade. Caixeta-Filho (2004) identifica que essas metodologias também buscam resolver problemas que envolvem balanço entre oferta e demanda.
Inicialmente, o mesmo autor define que o problema deve ser estruturado de forma diagramática, como ilustrado na Figura 2.

Com a estruturação do problema em forma diagramática, faz-se necessária a definição das variáveis de decisão. No caso do exemplo ilustrado na Figura 2, são as quantidades transportadas entre os fornecedores e a empresa e as quantidades transportadas entre a empresa e os pontos da demanda. Observa-se que existe uma relação de custo e a distância envolvida no processo. Estes entram como dados no problema, bem como a disponibilidade de fornecimento e a demanda do cliente. Em muitos casos, como o analisado no presente artigo, não existe um balanceamento entre oferta e demanda. Assim, é necessária a utilização de alguns artifícios na resolução do problema.

Com todos esses dados, a próxima etapa consiste na elaboração da função objetivo. Nesse caso, ela está relacionada em encontrar uma estrutura de suprimento e distribuição que represente um menor custo operacional possível.

Nos problemas de transporte, porém, existem algumas limitações que o modelo deve observar. Essas restrições englobam capacidade de transporte entre pontos, imposições governamentais, restrições tecnológicas e de acesso. Assim, o modelo também deve contemplar essas restrições a fim de atingir um resultado aplicável à realidade, dado que modelos são simplificações da realidade.

\section{Biodiesel e sua cadeia produtiva}

Holanda (2006) define o biodiesel como sendo a denominação genérica para combustíveis e aditivos provenientes de fontes renováveis de energia.

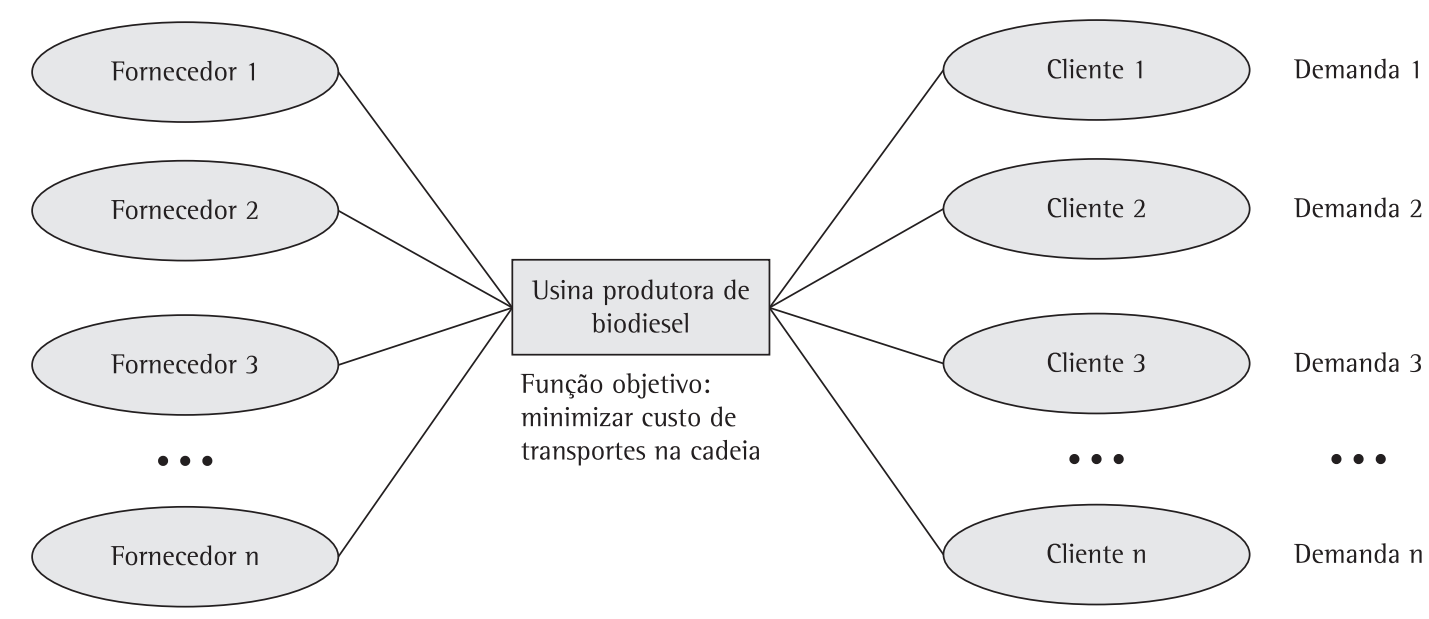

Figura 2. Esquema diagramático. 
Vale ressaltar que o biodiesel pode ser considerado um excelente aditivo verde para o óleo diesel, pois ele substitui o enxofre, garantindo a lubricidade do óleo diesel e diminui o impacto ambiental (HOLANDA, 2006).

A Figura 3 ilustra o funcionamento da CPB. Essa sequência de atividades culmina no produto final: o biodiesel. Como subprodutos dessa cadeia têm-se o farelo de oleaginosa e a glicerina, que podem servir de matéria-prima para outras cadeias produtivas de centenas de produtos.

Cada caixa ilustra um elo dessa rede, na qual é identificada a atividade realizada. Essas atividades são interligadas, formando a cadeia. Na Figura 3, a CPB foi dividida em duas partes: a cadeia principal (onde ocorre a transformação da matéria-prima em biodiesel e subprodutos) e a cadeia secundária (onde estão alocados os elos que apoiam essa transformação).
Assim, observa-se que o objetivo final dessa cadeia é a disponibilização de biodiesel para o mercado.

\section{Proposta do modelo de seleção de fornecedores}

Inicialmente, foram identificados os fatores de competitividade para a cadeia produtiva do biodiesel e seus fatores de certificação. De acordo com a revisão da bibliografia, foi elaborada uma lista de constructos, que nortearam o modelo de avaliação proposto. Esses constructos estão listados abaixo:

- Competitividade em cadeias produtivas;

- Sustentabilidade ambiental do negócio;

- Sustentabilidade social do negócio;

- Produtividade, confiabilidade e custos; e

- Transporte e seus custos.

Com base nesses dados, foi elaborada uma estrutura arborescente para auxiliar o agrupamento

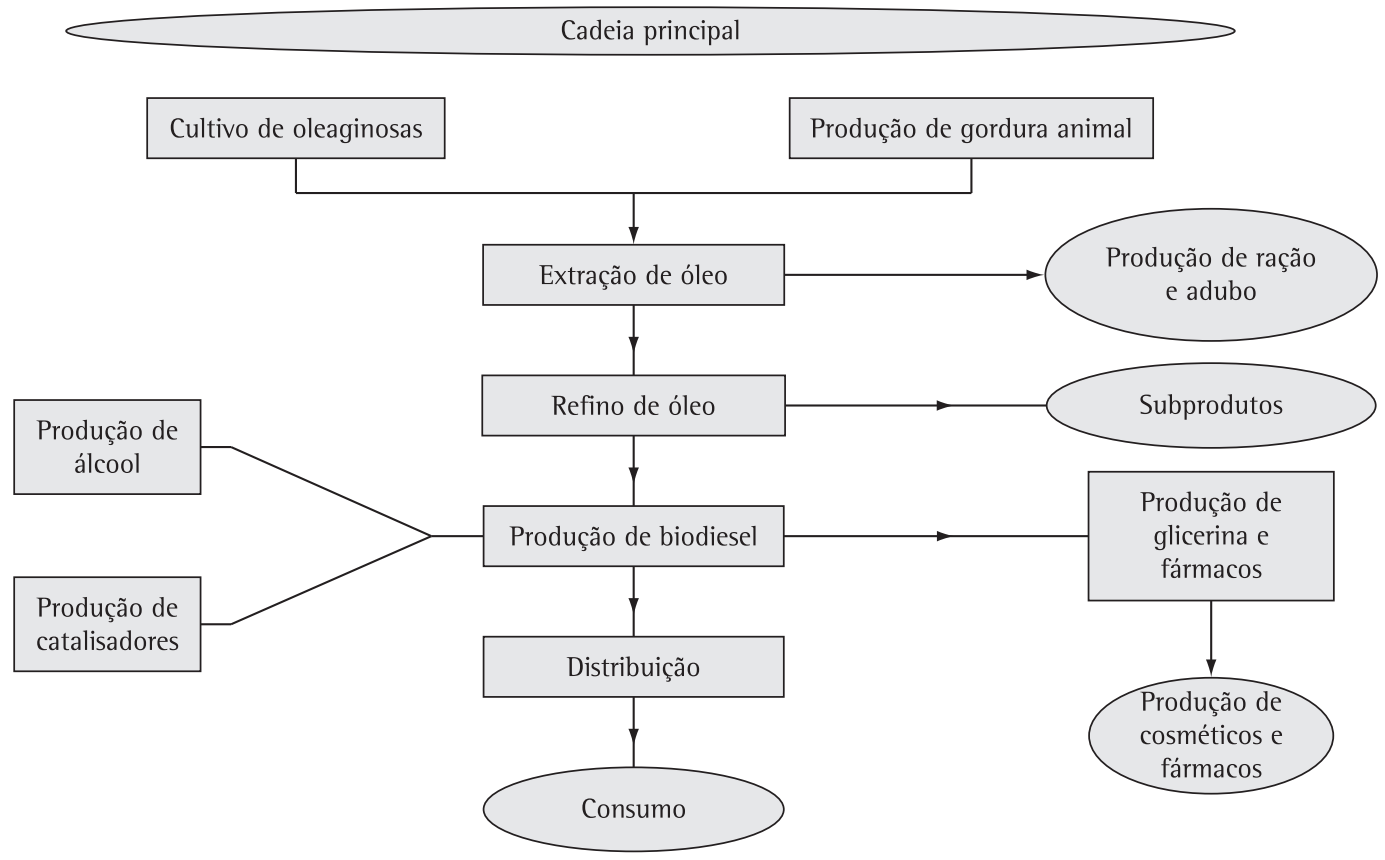

Cadeia secundária

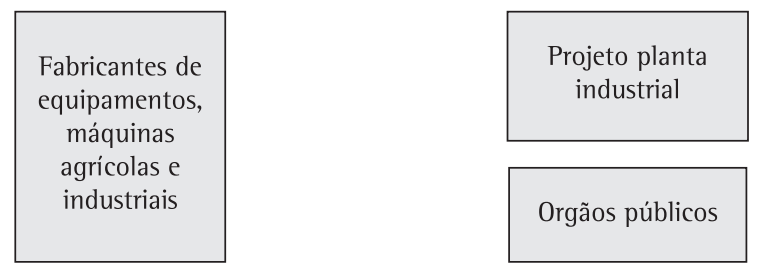

Fabricantes de micro e grandes usinas

Laboratórios e certificadoras

Figura 3. Cadeia produtiva do biodiesel. Fonte: Carmo (2007). 
desses fatores de acordo com sua correlação qualitativa. A Figura 4 ilustra a estrutura obtida. Os quesitos avaliados foram obtidos com base em entrevistas com especialistas e gestores da área.

Pela Figura 4, constata-se a existência de seis fatores para análise do fornecedor, que agrupam características desejáveis tanto para a competitividade da cadeia como para a adequação aos princípios de certificação elaborados no mundo.

Para a avaliação dos fornecedores para as usinas de biodiesel, optou-se pela utilização do modelo Smarter por ser de fácil implantação e manuseio, o que torna mais simples a usabilidade desse modelo no setor produtivo. Também, por não haver parâmetros suficientes para a definição dos pesos $\mathrm{W}_{\mathrm{i}}$ de cada ferramenta e cada grupo de fatores avaliados, para evitar erros de modelagem e elicitação por parte dos gestores, que não conhecem, em muitos casos, as diretrizes de certificação e competitividade. Essa decisão foi tomada pelo fato de esse modelo trazer uma visão inovadora de análise de fornecedores, ficando difícil a avaliação por parte do mercado, tendo em vista o desconhecimento dos fatores considerados pelo mundo.

A primeira etapa do modelo consiste na construção de uma tabela de avaliação de consequências, que podem ser imensuráveis, como as características do tipo de produto fornecido ou grandezas mensuráveis, como o índice de Desenvolvimento Humano (IDH) e o Produto Interno Bruto (PIB) do município.

0 primeiro grupo de fatores engloba as características de competitividade desejáveis para a CPB. Foram identificadas quatro características principais que os fornecedores devem possuir. Para cada uma dessas características, foram definidos níveis de impacto, o que é ilustrado no Quadro 1.

Existem características que possuem três níveis de impacto e outras que possuem dois. A divisão dos níveis de impacto foi realizada através da técnica intervalar média.

A primeira característica é o tipo de produto fornecido pelo fornecedor. Nesse caso, do ponto de vista da usina, é mais interessante receber o óleo vegetal refinado. Além de ser mais importante, os elos anteriores têm maior possibilidade de agregação de valor ao seu produto, melhorando a qualidade de vida dos agricultores, requisito imposto pelas diretrizes de certificação. A segunda característica é a existência ou não de uma cooperativa organizada. lsso se faz necessário para dar maior confiabilidade ao sistema de fornecimento, além de facilitar o desenvolvimento da agricultura familiar. Há ainda a questão da existência ou não de incentivos

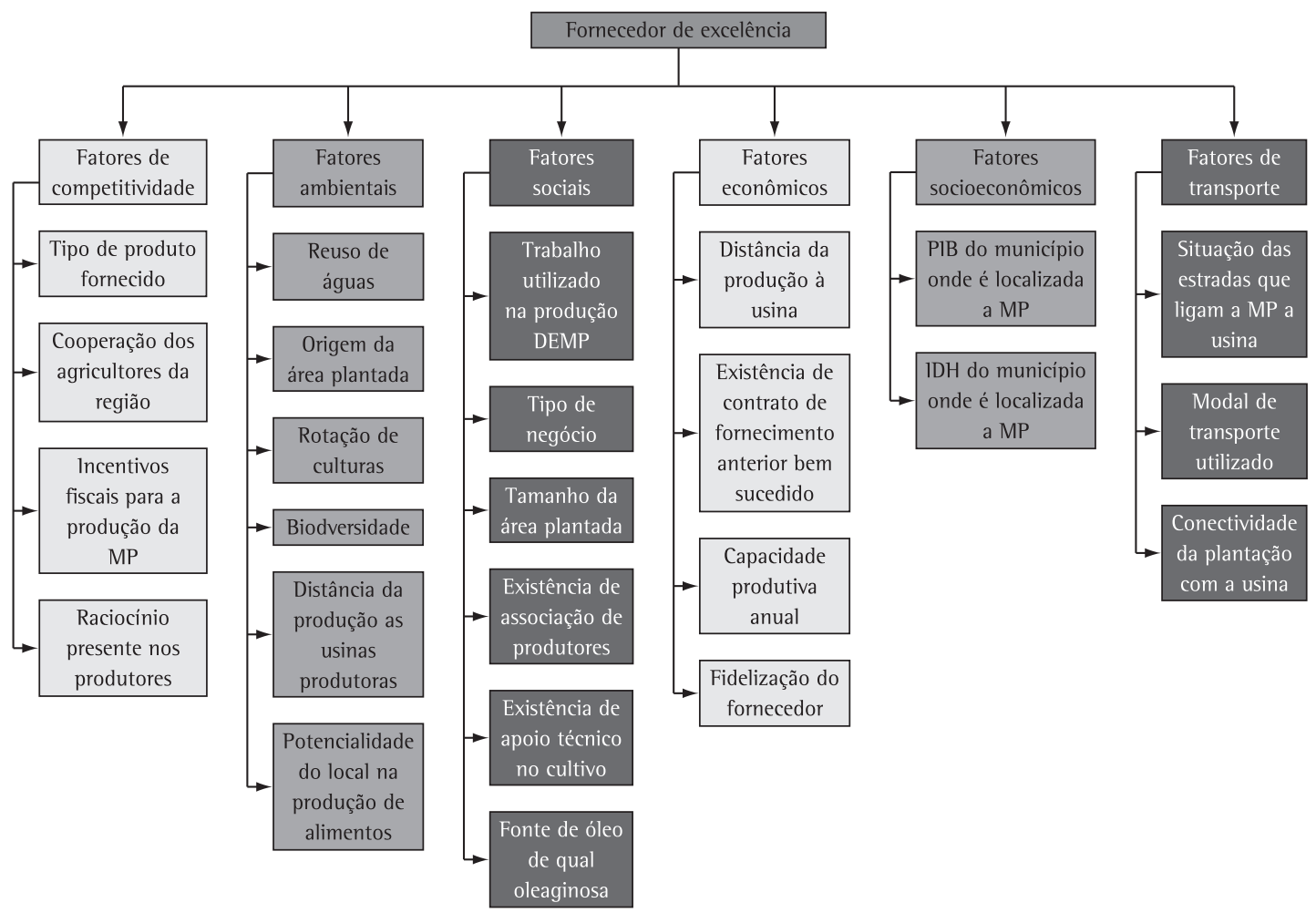

Figura 4. Estrutura arborescente do modelo. 
Quadro 1. Fatores de competitividade e seus níveis de impacto.

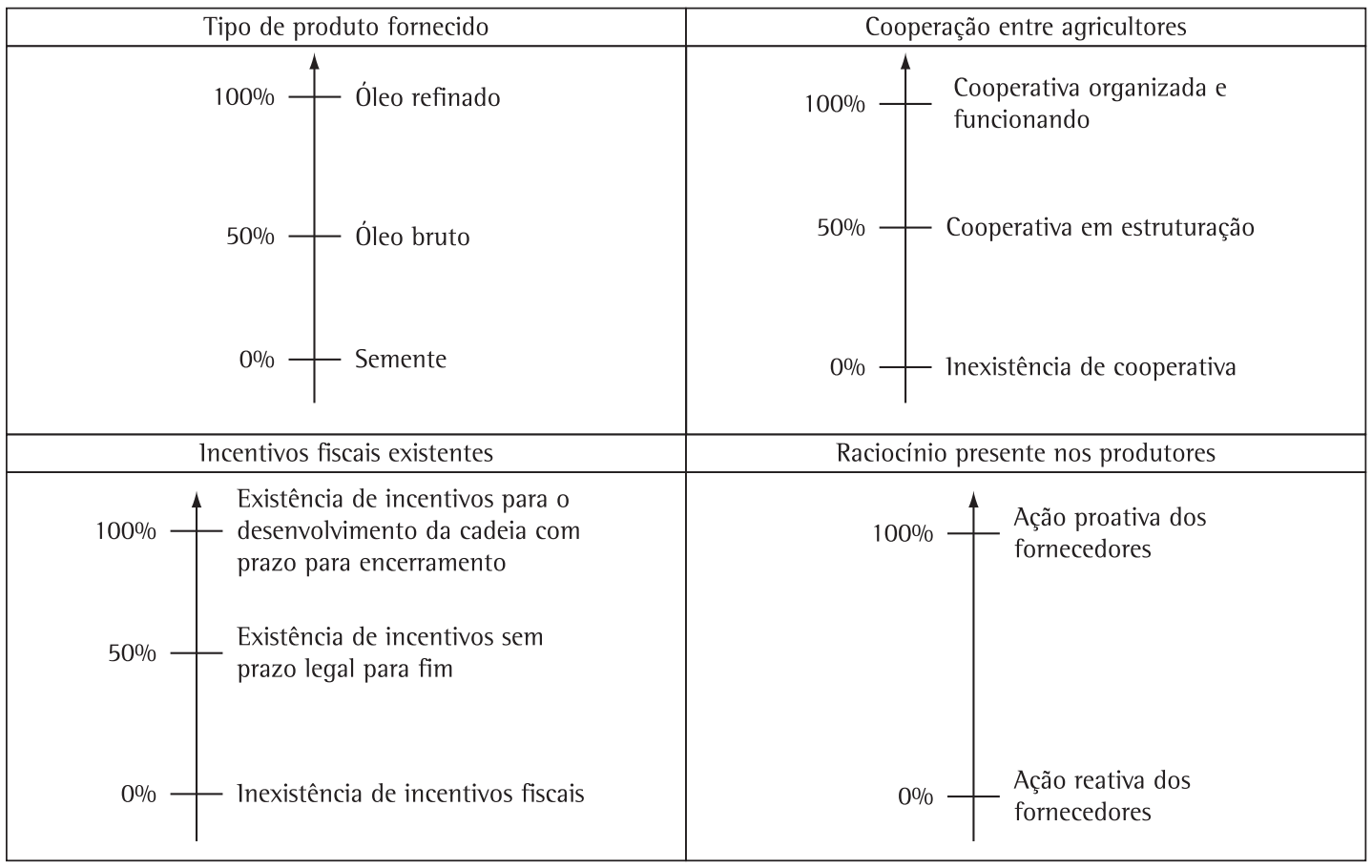

fiscais. É interessante que haja incentivos ficais, mas eles devem ter prazo de vigência, para que a cadeia não fique dependente desses incentivos. lsso pode minar o seu desenvolvimento. Por último, tem-se a característica de raciocínio. Nesse caso, uma análise mais qualitativa visa identificar qual a postura do fornecedor, se ele busca a solução para os problemas do seu elo ou, simplesmente, espera ações governamentais para alcançar essa solução. Fornecedores mais ativos são mais confiáveis no fornecimento e para a manutenção da competitividade da cadeia.

No segundo grupo de fatores, foram avaliados os ambientais, que são um dos requisitos para futura certificação da cadeia de valor do biodiesel. Nesse ponto, procura-se avaliar o impacto ambiental causado pela produção de matéria-prima dentro dos ecossistemas. Para tanto, foram identificadas cinco características para formar esse fator, de acordo com as diretrizes internacionais observadas.

Para cada uma dessas características, foram definidos níveis de impacto, ilustrados no Quadro 2.

A primeira característica visa identificar a preocupação do fornecedor quanto ao reuso de águas, uma das diretrizes definidas pelos países europeus. Outra característica é a origem da área plantada, que deve observar o zoneamento da Embrapa para identificação das áreas passíveis de serem cultivadas, sem haver desmatamento.
Outro ponto é se o fornecedor realiza ou não a rotação de culturas. Isso visa identificar se há a preocupação ou não com o desgaste do solo e projetos de reflorestamento. Ainda foi contemplada a característica de potencialidade da área para a produção de alimentos, evitando áreas que podem ser utilizadas para esse fim, buscando diminuir o impacto da produção dos biocombustíveis na segurança alimentar.

0 terceiro grupo de fatores engloba os fatores sociais, avaliando o impacto da produção de matéria-prima (MP) para a sociedade. Essas características buscam identificar os benefícios da produção da MP para a sociedade, observando o impacto na qualidade de vida do entorno das plantações. Esse também é um quesito constatado quando se fala na certificação da cadeia de valor do biodiesel. 0 Quadro 3 ilustra os níveis de impacto desses fatores.

Essas características identificam quanto a produção das matérias-primas traz 0 desenvolvimento social nos elos anteriores. Busca-se avaliar se existe ou não trabalho escravo, se trata de agricultura familiar ou não, qual o tamanho das áreas, identificação da existência de apoio técnico no cultivo e se a MP serve ou não como fonte de alimentação.

0 quarto grupo de fatores engloba os fatores econômicos, visando privilegiar matérias-primas 
Quadro 2. Fatores ambientais e seus níveis de impacto.

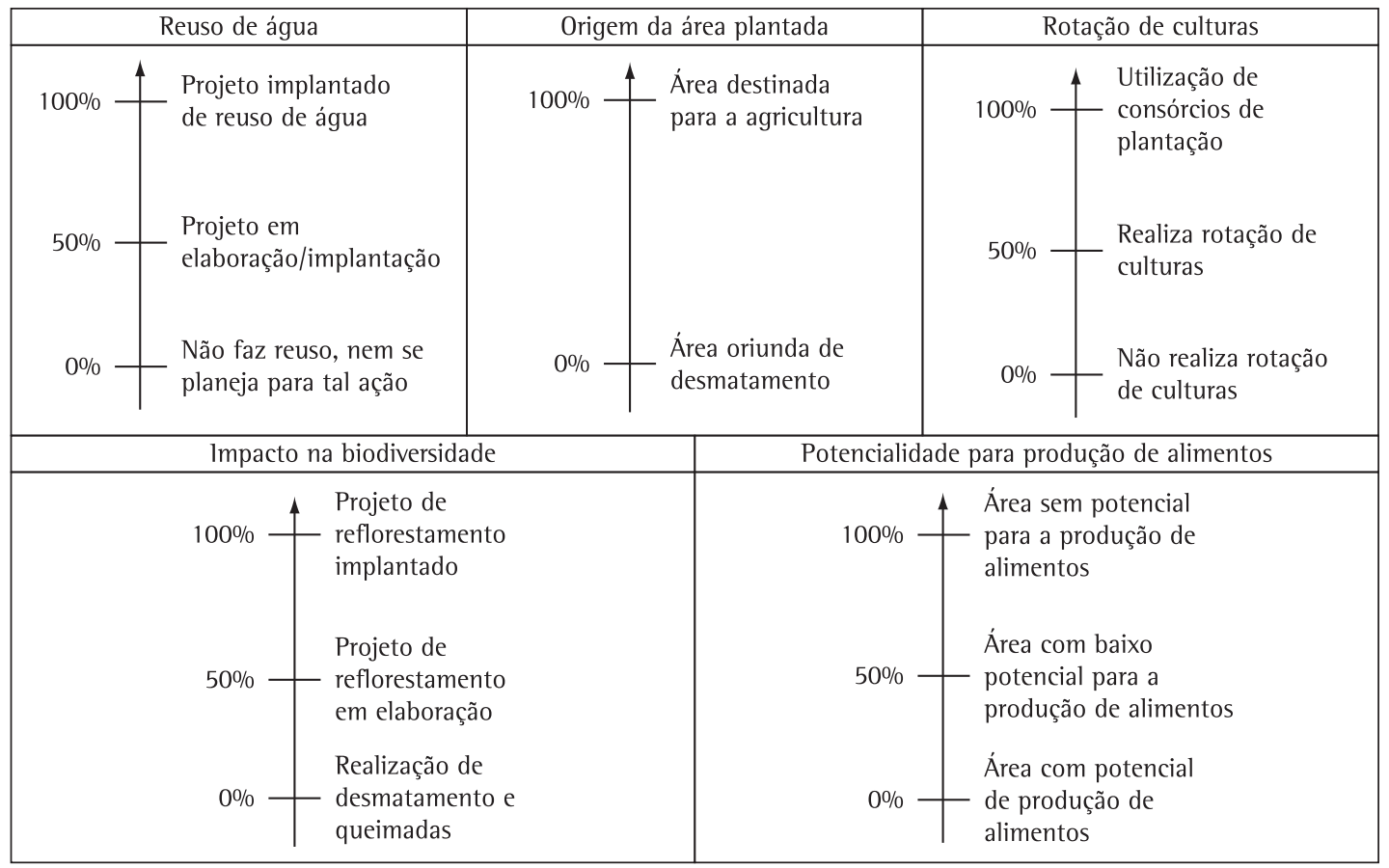

Quadro 3. Fatores sociais e seus níveis de impacto.

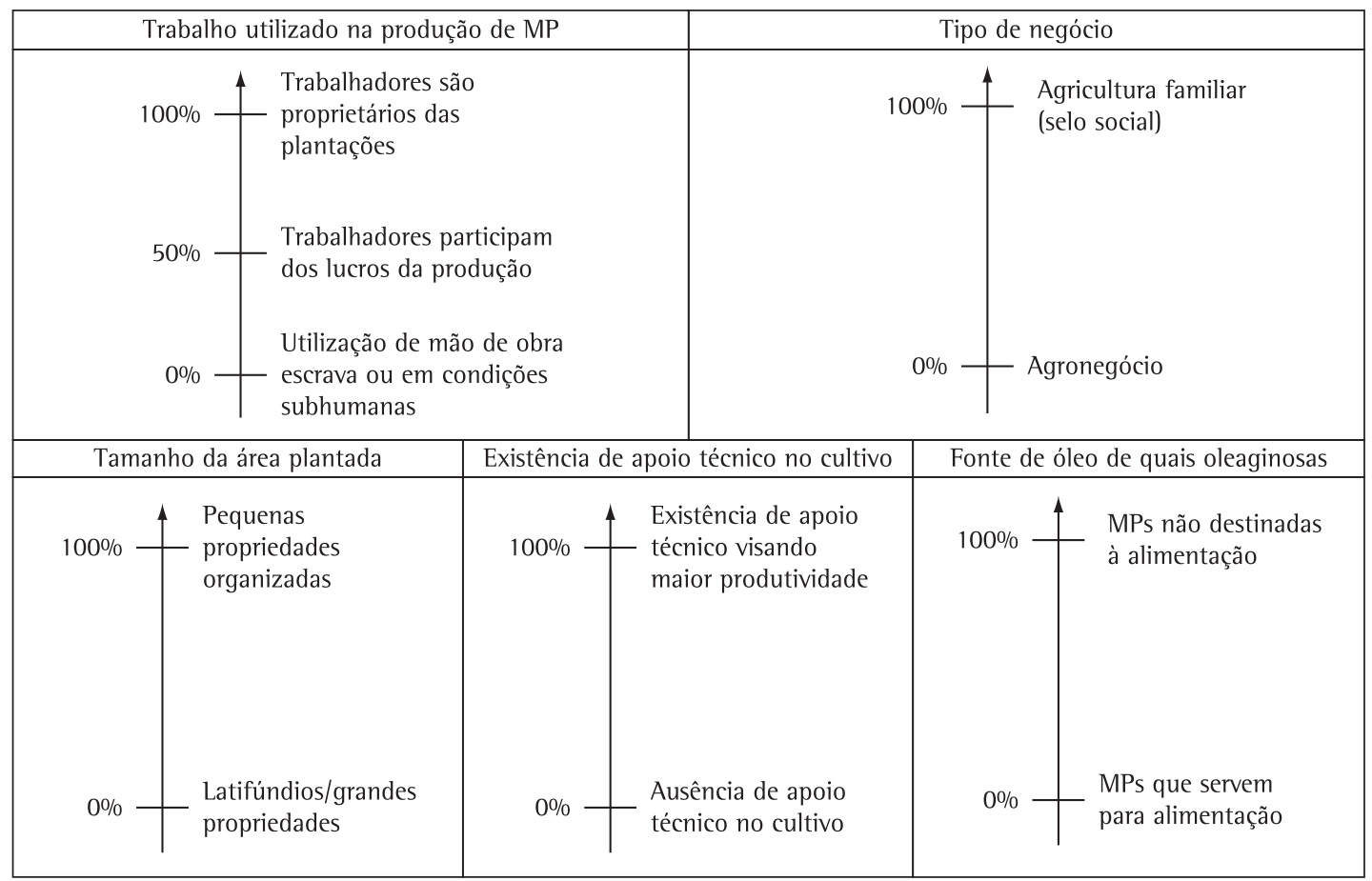

com menor custo econômico no transporte. Observam-se também características quanto à confiabilidade do fornecimento, para evitar a falta de MP nessa cadeia produtiva. 0 Quadro 4 ilustra os possíveis níveis de impacto das características englobadas no fator econômico.

0 fator econômico se reporta às variáveis que visam a produtividade da cadeia e os custos envolvidos no 
Quadro 4. Fatores econômicos e seus níveis de impacto.

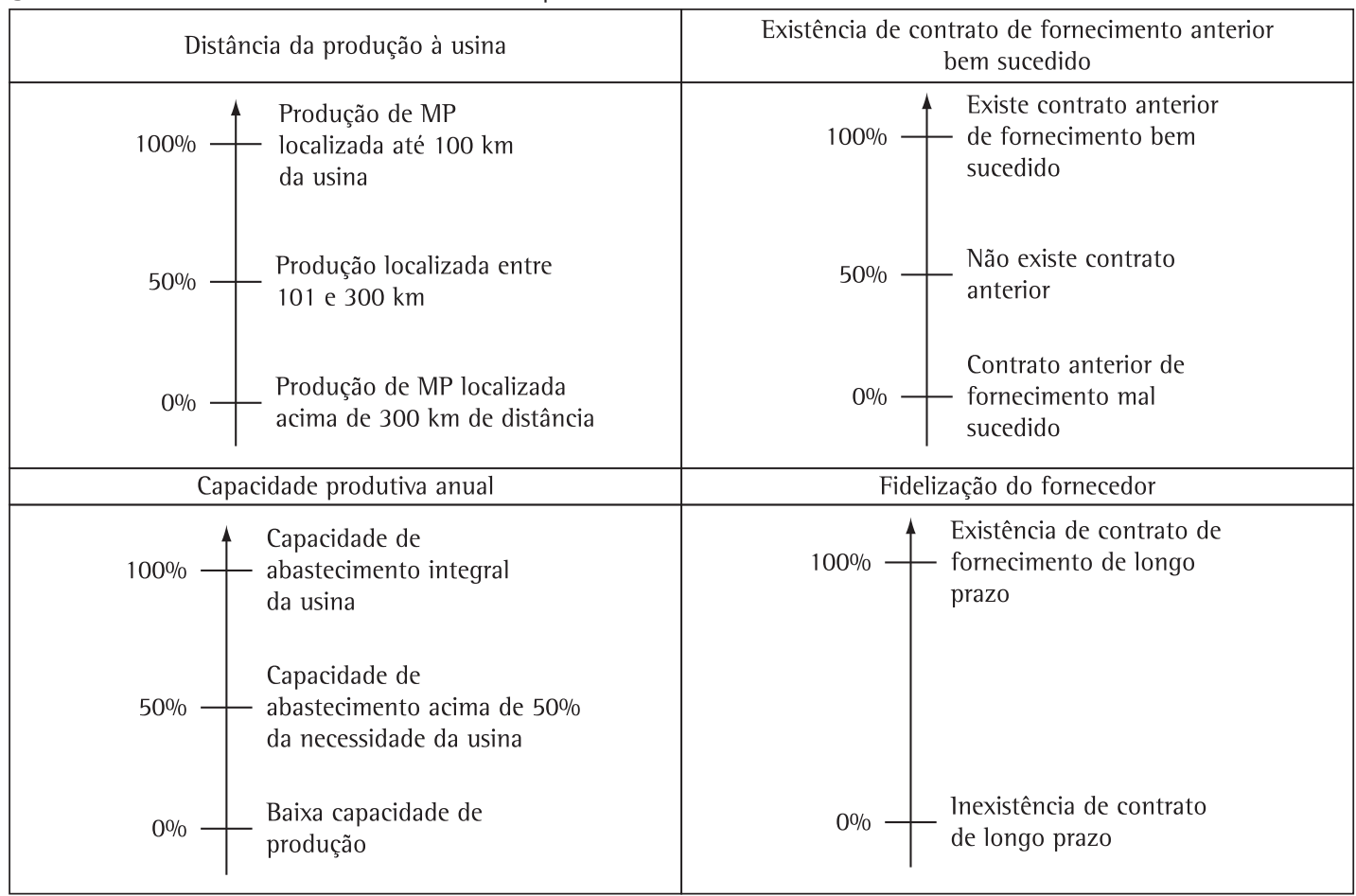

transporte. Busca-se identificar os fornecedores mais confiáveis (grande problema de falta de MP), qual sua capacidade de fornecimento e qual a distância deles até as unidades produtoras de biodiesel.

0 quinto grupo de fatores engloba os fatores socioeconômicos, visando priorizar plantações localizadas em municípios pobres, porém que possuam maior índice de desenvolvimento humano. Essa escolha foi feita devido a se pensar que sejam preferíveis municípios que invistam no seu desenvolvimento humano e social, mesmo que não tenham alto poder aquisitivo.

Esse fator também busca a consonância com os critérios de inclusão social e aumento da qualidade de vida da população no entorno, que são requisitos para a certificação da cadeia de valor do biodiesel. 0 Quadro 5 ilustra os níveis de impacto das características agrupadas nesse fator.

Essas características ainda não foram definidas, mas o interessante é que municípios com alto índice de desenvolvimento humano e considerados "pobres" sejam privilegiados, a fim de promover seu desenvolvimento e privilegiar os que buscam a melhoria de sua população.

Por último, existe o fator de transporte, que engloba características quanto à conectividade e situação da ligação entre as fontes de matéria-prima até as usinas de destino das mesmas. Busca-se selecionar os modais com menor custo de transporte, a melhor infraestrutura disponivel e a conectividade entre as localidades produtoras e consumidoras. 0 Quadro 6 ilustra os níveis de impacto dessas características.

A segunda etapa do modelo Smarter é observar a existência de alguma variável controlada por outra. Nesse caso, na construção do modelo, já houve essa preocupação, a fim de se evitar a etapa. Existe, porém, a possibilidade de haver a dependência entre os fatores socioeconômicos, mas essas características não serão retiradas por sua importância no estudo.

A terceira etapa consiste no ordenamento dos critérios por ordem de preferência. Para a definição dos pesos, constata-se a inexistência de informações quantitativas para o ordenamento das importâncias. Assim, foi escolhida a metodologia ROC (Rank Order Centroid) para o ordenamento e atribuição dos pesos respectivos.

Essa etapa foi realizada em duas fases em que, na primeira, foram ordenados os pesos por fator e, em seguida, ordenados os seus pesos.

No modelo ROC, o primeiro passo é a definição da ordem de importância de cada característica em cada um dos fatores levantados. Vale ressaltar que o peso dessas características deve somar 100\%. No caso do artigo, a ordem de importância foi obtida através das entrevistas realizadas com os gestores anteriormente. 
Quadro 5. Fatores socioeconômicos e seus níveis de impacto.

\begin{tabular}{|c|c|c|c|}
\hline \multicolumn{2}{|c|}{$\begin{array}{l}\text { PIB do município onde é localizada a produção de } \\
\text { MP }\end{array}$} & \multicolumn{2}{|c|}{$\begin{array}{l}\text { IDH do município onde é localizada a produção da } \\
\text { MP }\end{array}$} \\
\hline $100 \%$ & $\begin{array}{l}\text { Município com baixo } \\
\text { PIB }\end{array}$ & $100 \%$ & $\underset{1 \mathrm{DH}}{\mathrm{f}}$ \\
\hline $50 \%$ & $\begin{array}{l}\text { Município com PIB } \\
\text { intermediário }\end{array}$ & $50 \%$ & $\begin{array}{l}\text { Município com IDH } \\
\text { intermediário }\end{array}$ \\
\hline $0 \%$ & - Municípios ricos & $0 \%$ & - Baixo IDH \\
\hline
\end{tabular}

Quadro 6. Fatores de transportes e seus níveis de impacto.

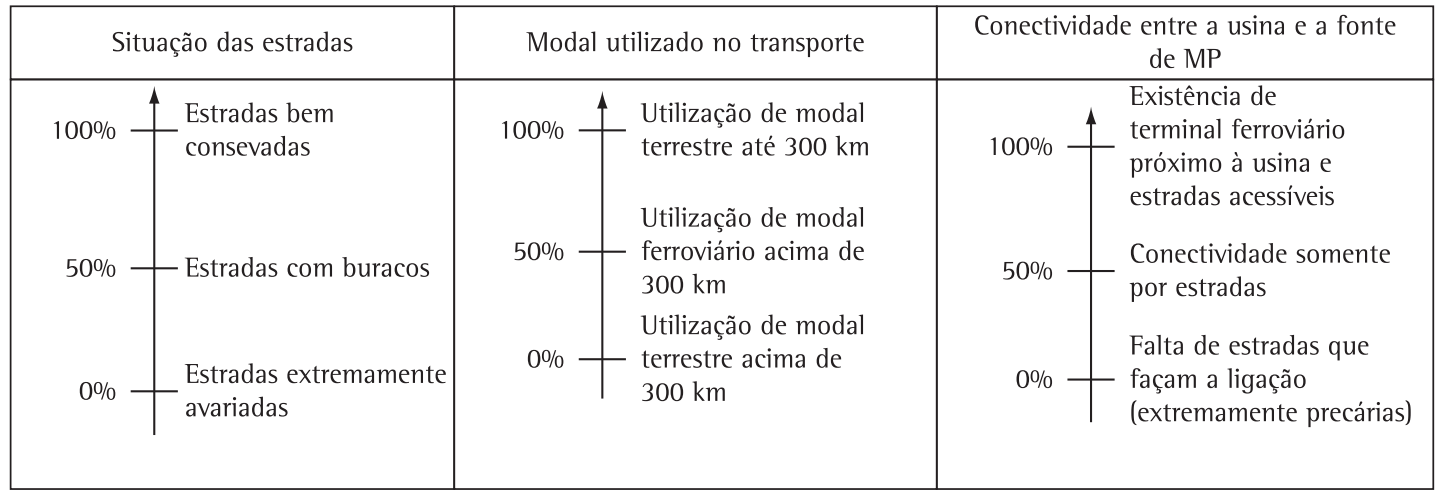

Assim, foram elaborados os pesos para cada característica. Para o primeiro fator, chamado de competitividade, foi adotada a seguinte ordem de importância das características dentro do fator:

- Produto fornecido > Existência de cooperação > Incentivos fiscais $>$ Raciocínio produtores.

Com base nessa ordem de preferência, foram adotados pesos relativos a cada característica dentro desse fator, ilustrado na Tabela 1.

No segundo fator, a ordem de preferência é dada a seguir:

- Potencialidade prod. alim. > Rot. cultura > Reuso de água $>$ Biodiversidade $>$ Origem da terra.

A adoção dessa ordem de importância foi atribuída segundo a opinião de especialistas consultados e com base em pesquisas bibliográficas.

Com base nessa ordem de preferência, foram adotados os pesos relativos a cada característica dentro desse fator, ilustrado na Tabela 2.

No terceiro fator, a ordem de preferência é dada a seguir:

- Tipo de negócio > Mão de obra utilizada > Existência de apoio técnico $>$ Tamanho da área > Tipo de oleaginosa.
A adoção dessa ordem de importância foi atribuída segundo impressões pessoais de visitas realizadas e estudos.

Com base nessa ordem de preferência, foram adotados os pesos relativos a cada característica dentro desse fator, ilustrado na Tabela 3.

No quarto fator, o econômico, a ordem de preferência é dada a seguir:

- Fidelização do produtor > Existência de contrato anterior > Capacidade produtiva > Distância até a usina.

Para a definição dessa ordem de preferência, buscou-se priorizar um fornecimento constante, pois foi observado que muitas usinas estão paradas por falta de matéria-prima para a produção. A Tabela 4 ilustra os valores obtidos para os pesos.

No quinto fator, o socioeconômico, buscou-se priorizar os produtores localizados em municípios com maior índice de desenvolvimento humano, pois este ilustra a qualidade de vida da população, critério mais importante para certificação.

- Índice de Desenvolvimento Humano > Produto Interno Bruto do município. 
Tabela 1. Pesos referentes ao fator competitividade.

\begin{tabular}{ccc}
\hline Característica & $\begin{array}{c}\text { Formulação } \\
\text { utilizada }\end{array}$ & $\begin{array}{c}\text { Peso } \\
\text { encontrado } \\
(\%)\end{array}$ \\
\hline $\begin{array}{c}\text { Produto fornecido } \\
\text { cooperação }\end{array}$ & $\mathrm{w} 11=\frac{1}{4} \cdot \sum_{\mathrm{i}=1}^{\mathrm{i}=4} \frac{1}{\mathrm{i}}$ & 52,08 \\
$\begin{array}{c}\text { Incentivos fiscais } \\
\text { w12 }\end{array}$ & $\mathrm{w} 13=\frac{1}{4} \cdot \sum_{\mathrm{i}=2}^{\mathrm{i}=4} \frac{1}{4} \cdot \sum_{\mathrm{i}=3}^{\mathrm{i}=4} \frac{1}{\mathrm{i}}$ & 27,08 \\
Raciocínio produtores & $\mathrm{w} 14=\frac{1}{4} \cdot \sum_{\mathrm{i}=4}^{\mathrm{i}=4} \frac{1}{\mathrm{i}}$ & \\
\hline
\end{tabular}

Tabela 2. Pesos referentes ao fator ambiental.

\begin{tabular}{ccc}
\hline Característica & $\begin{array}{c}\text { Formulação } \\
\text { utilizada }\end{array}$ & $\begin{array}{c}\text { Peso } \\
\text { encontrado } \\
(\%)\end{array}$ \\
\hline $\begin{array}{c}\text { Potencialidade para } \\
\text { produção de alimentos }\end{array}$ & $\mathrm{w} 21=\frac{1}{5} \cdot \sum_{\mathrm{i}=1}^{\mathrm{i}=5} \frac{1}{\mathrm{i}}$ & 45,67 \\
Rotação de cultura & $\mathrm{w} 22=\frac{1}{5} \cdot \sum_{\mathrm{i}=2}^{\mathrm{i}=5} \frac{1}{\mathrm{i}}$ & 25,67 \\
Reuso de água & $\mathrm{w} 23=\frac{1}{5} \cdot \sum_{\mathrm{i}=3}^{\mathrm{i}=5} \frac{1}{\mathrm{i}}$ & 15,67 \\
$\begin{array}{c}\text { Impacto na } \\
\text { biodiversidade }\end{array}$ & $\mathrm{w} 24=\frac{1}{5} \cdot \sum_{\mathrm{i}=4}^{\mathrm{i}=5} \frac{1}{\mathrm{i}}$ & 9,00 \\
Origem da terra & $\mathrm{w} 25=\frac{1}{5} \cdot \sum_{\mathrm{i}=5}^{\mathrm{i}=5} \frac{1}{\mathrm{i}}$ & 4,00 \\
\hline
\end{tabular}

Tabela 3. Pesos referentes ao fator social.

\begin{tabular}{|c|c|c|}
\hline Característica & $\begin{array}{c}\text { Formulação } \\
\text { utilizada }\end{array}$ & $\begin{array}{c}\text { Peso } \\
\text { encontrado } \\
(\%)\end{array}$ \\
\hline Tipo de negócio & $\mathrm{w} 31=\frac{1}{5} \cdot \sum_{\mathrm{i}=1}^{\mathrm{i}=5} \frac{1}{\mathrm{i}}$ & 45,67 \\
\hline Mão de obra utilizada & $\mathrm{w} 32=\frac{1}{5} \cdot \sum_{i=2}^{i=5} \frac{1}{\mathrm{i}}$ & 25,67 \\
\hline $\begin{array}{l}\text { Existência de apoio } \\
\text { técnico }\end{array}$ & $w 33=\frac{1}{5} \cdot \sum_{i=3}^{i=5} \frac{1}{i}$ & 15,67 \\
\hline $\begin{array}{c}\text { Tamanho da área } \\
\text { plantada }\end{array}$ & $\mathrm{w} 34=\frac{1}{5} \cdot \sum_{\mathrm{i}=4}^{\mathrm{i}=5} \frac{1}{\mathrm{i}}$ & 9,00 \\
\hline Tipo de oleaginosa & $\mathrm{w} 35=\frac{1}{5} \cdot \sum_{\mathrm{i}=5}^{\mathrm{i}=5} \frac{1}{\mathrm{i}}$ & 4,00 \\
\hline
\end{tabular}

Tabela 4. Pesos referentes ao fator econômico.

\begin{tabular}{|c|c|c|}
\hline Característica & $\begin{array}{c}\text { Formulação } \\
\text { utilizada }\end{array}$ & $\begin{array}{c}\text { Peso } \\
\text { encontrado } \\
(\%)\end{array}$ \\
\hline Fidelização do produtor & $\mathrm{w} 41=\frac{1}{4} \cdot \sum_{\mathrm{i}=1}^{\mathrm{i}=4} \frac{1}{\mathrm{i}}$ & 52,08 \\
\hline $\begin{array}{c}\text { Existência de contrato } \\
\text { anterior }\end{array}$ & $\mathrm{w} 42=\frac{1}{4} \cdot \sum_{\mathrm{i}=2}^{\mathrm{i}=4} \frac{1}{\mathrm{i}}$ & 27,08 \\
\hline Capacidade produtiva & $\mathrm{w} 43=\frac{1}{4} \cdot \sum_{\mathrm{i}=3}^{\mathrm{i}=4} \frac{1}{\mathrm{i}}$ & 14,58 \\
\hline Distância até a usina & $\mathrm{w} 44=\frac{1}{4} \cdot \sum_{\mathrm{i}=4}^{\mathrm{i}=4} \frac{1}{\mathrm{i}}$ & 6,25 \\
\hline
\end{tabular}

Assim, com essa ordem estabelecida, foram calculados os pesos para essas duas características, ilustrado na Tabela 5.

Por último, observa-se o sexto fator, o fator transporte, onde se buscou priorizar os modais que, em teoria, possuem menor custo.

- Modal utilizado no transporte > Conectividade do município > Situação das estradas.

Assim, com essa ordem estabelecida, foram calculados os pesos para essas três características, ilustrado na Tabela 6.

Como descrito anteriormente, essa etapa do modelo foi realizada em duas partes, onde a primeira encontra os pesos referentes às características em cada uma dos fatores e, a segunda, define os pesos referentes a cada uma dos fatores. Para tanto, também se utilizou a metodologia ROC para a definição desses pesos.

Para a definição da ordem de importância de cada um dos fatores, Carmo (2009) levou em consideração alguns pressupostos:

- Constatou-se que várias usinas estão trabalhando abaixo de sua capacidade produtiva ou não estão operando. Por esse motivo, adotou-se o fator mais importante como o econômico, por contemplar a confiabilidade de fornecimento para a cadeia;

- 0 segundo fator mais importante é a competitividade, que define a viabilidade futura da cadeia;

- 0 terceiro fator mais importante é o fator ambiental por considerar os impactos no ambiente e a segurança alimentar, elemento crítico em toda bibliografia consultada;

- 0 quarto fator mais importante é o fator social, por ser um elemento vital nas normas de certificação existentes;

- 0 quinto fator é o transporte, visando uma maior eficiência do mesmo; e 
Tabela 5. Pesos referentes ao fator socioeconômico.

\begin{tabular}{ccc}
\hline Característica & $\begin{array}{c}\text { Formulação } \\
\text { utilizada }\end{array}$ & $\begin{array}{c}\text { Peso } \\
\text { encontrado } \\
(\%)\end{array}$ \\
\hline IDH município & $\mathrm{w} 51=\frac{1}{2} \cdot \sum_{\mathrm{i}=1}^{\mathrm{i}=2} \frac{1}{\mathrm{i}}$ & 75,00 \\
PIB município & $\mathrm{w} 52=\frac{1}{2} \cdot \sum_{\mathrm{i}=2}^{\mathrm{i}=2} \frac{1}{\mathrm{i}}$ & 25,00 \\
\hline
\end{tabular}

Tabela 6. Pesos referentes ao fator transporte.

\begin{tabular}{ccc}
\hline Característica & $\begin{array}{c}\text { Formulação } \\
\text { utilizada }\end{array}$ & $\begin{array}{c}\text { Peso } \\
\text { encontrado } \\
(\%)\end{array}$ \\
\hline $\begin{array}{c}\text { Modal utilizado no } \\
\text { transporte }\end{array}$ & $\mathrm{w} 61=\frac{1}{3} \cdot \sum_{\mathrm{i}=1}^{\mathrm{i}=3} \frac{1}{\mathrm{i}}$ & 61,11 \\
$\begin{array}{c}\text { Conectividade do } \\
\text { município }\end{array}$ & $\mathrm{w} 62=\frac{1}{3} \cdot \sum_{\mathrm{i}=2}^{\mathrm{i}=3} \frac{1}{\mathrm{i}}$ & 27,78 \\
Situação das estradas & $\mathrm{w} 63=\frac{1}{3} \cdot \sum_{\mathrm{i}=3}^{\mathrm{i}=3} \frac{1}{\mathrm{i}}$ & 11,11 \\
\hline
\end{tabular}

- Por último, observa-se o fator socioeconômico, que complementa a análise do ponto de vista macro.

Assim, estabeleceu-se a ordem de preferência dos fatores para seleção dos fornecedores para a cadeia produtiva do biodiesel, ilustrado abaixo.

- Fator econômico > Fator competitividade $>$ Fator ambiental $>$ Fator social $>$ Fator transporte $>$ Fator socioeconômico.

Assim, com essa ordem estabelecida, foram calculados os pesos para essas três características, ilustrado na Tabela 7 .

Com os pesos obtidos para cada característica e para cada fator de avaliação, o passo seguinte é a elaboração da fórmula de agregação aditiva. Para isso, tomam-se as seguintes definições:

- $\mathrm{C}_{\mathrm{ij}}=$ característica $\mathrm{i}$, no fator $\mathrm{j}$;

- $\mathrm{W}_{\mathrm{ij}}=$ peso da característica $\mathrm{i}$ no fator $\mathrm{j}$;

Com essas duas definições, estabelece-se a avaliação dos fornecedores segundo a Equação abaixo:

$$
\sum_{i} \sum_{j} C_{i j} \cdot W_{i j}
$$

Para a avaliação global do fornecedor, é necessário colocar ainda a ponderação de cada fator. Para tanto, seguem as definições abaixo:

- $F_{j}=$ Fator de índice $\mathrm{j}$;

- $\mathrm{W}_{\mathrm{j}}=$ Peso do fator $\mathrm{F}$ com índice $\mathrm{j}$;
Tabela 7. Pesos referentes a fatores para seleção de fornecedores.

\begin{tabular}{ccc}
\hline Caracteristica & $\begin{array}{c}\text { Formulação } \\
\text { utilizada }\end{array}$ & $\begin{array}{c}\text { Peso } \\
\text { encontrado } \\
(\%)\end{array}$ \\
\hline Fator econômico & $\mathrm{w} 71=\frac{1}{6} \cdot \sum_{\mathrm{i}=1}^{\mathrm{i}=6} \frac{1}{\mathrm{i}}$ & 40,83 \\
Fator competitividade & $\mathrm{w} 72=\frac{1}{6} \cdot \sum_{\mathrm{i}=2}^{\mathrm{i}=6} \frac{1}{\mathrm{i}}$ & 24,17 \\
Fator ambiental & $\mathrm{w} 73=\frac{1}{6} \cdot \sum_{\mathrm{i}=3}^{\mathrm{i}=6} \frac{1}{\mathrm{i}}$ & 15,83 \\
Fator social & $\mathrm{w} 74=\frac{1}{6} \cdot \sum_{\mathrm{i}=4}^{\mathrm{i}=6} \frac{1}{\mathrm{i}}$ & 10,28 \\
Fator transporte & $\mathrm{w} 75=\frac{1}{6} \cdot \sum_{\mathrm{i}=5}^{\mathrm{i}=6} \frac{1}{\mathrm{i}}$ & \\
& & \\
Fator socioeconômico & $\mathrm{w} 76=\frac{1}{6} \cdot \sum_{\mathrm{i}=6}^{\mathrm{i}=6} \frac{1}{\mathrm{i}}$ & 2,78
\end{tabular}

Assim, para uma avaliação global, observa-se a equação abaixo:

$W_{i}=\sum_{j=1}^{n} F_{j} \cdot W_{j} \cdot\left(\sum_{i=1}^{k} \sum_{j=1}^{k} C_{i j} \cdot W_{i j}\right)$

onde $\mathrm{W}_{\mathrm{i}}=$ avaliação do fornecedor, $\mathrm{n}$ = número de fatores e $\mathrm{k}$ = número de características por fator.

\section{Modelo de otimização}

A presente etapa do trabalho tem por objetivo a apresentação da modelagem matemática utilizada para fazer a otimização dentro da cadeia produtiva do biodiesel. Esse modelo tem por foco a usina produtora, por ser entendido que a mesma é responsável pela governança dessa cadeia.

A Figura 5 ilustra a estruturação do problema para a otimização do sistema.

0 Quadro 7 traz a descrição das variáveis do modelo.

Pela Figura 5, observa-se a existência de fornecedores de matéria-prima. Associados aos mesmos, existe uma distância $d_{i j}$ entre o fornecedor e a usina produtora de biodiesel e uma variável $X_{i j}$, que ilustra a quantidade de MP transportada entre o fornecedor i e a usina j. Cada fornecedor i possui uma capacidade $\mathrm{O}_{i}$ de fornecimento definida. Existe ainda um valor de custo associado ao transporte expresso em $\$ / 1 . \mathrm{km}$, chamado de $\beta$.

Por parte do elo que contém as usinas, existe um parâmetro associado a elas, que é a sua capacidade produtiva, expressa por $\mathrm{C}_{\mathrm{j}}$. 
$\mathrm{O}_{\mathrm{i}}=$ Capacidade do fornecedor $\mathrm{i}$

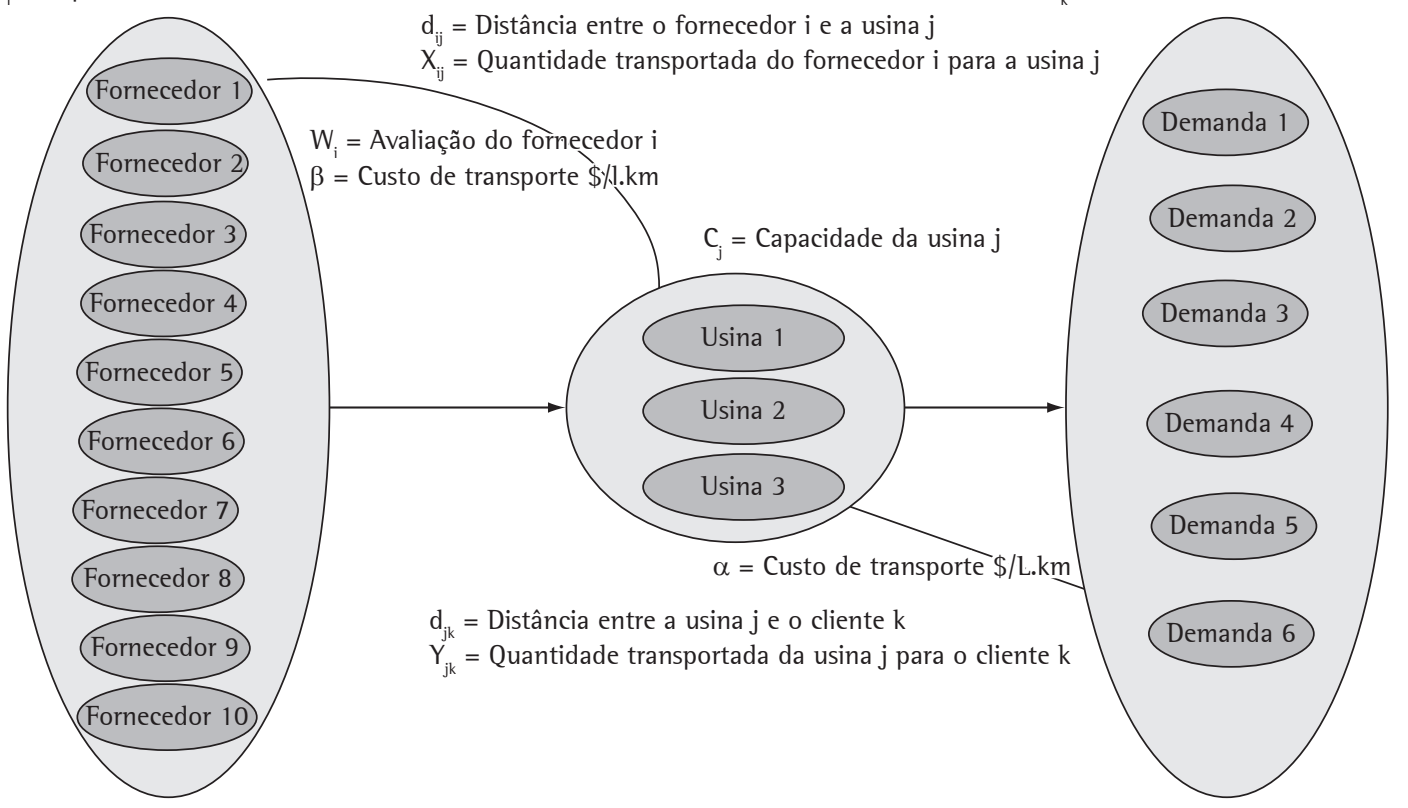

Figura 5. Estruturação do problema.

Quadro 7. Descrição das variáveis do modelo.

\begin{tabular}{|ccc|}
\hline Variável & Nomenclatura & Tipo \\
\hline Distância entre o fornecedor e a usina & $\mathrm{d}_{\mathrm{ij}}$ & Parâmetro \\
Quantidade de óleo transportado entre fornecedor e usina & $\mathrm{X}_{\mathrm{ij}}$ & Variável de decisão \\
Capacidade do fornecedor & $\mathrm{O}_{\mathrm{i}}$ & Parâmetro \\
Custo associado ao transporte & $\beta$ & Parâmetro \\
Capacidade da usina & $\mathrm{C}_{\mathrm{j}}$ & Parâmetro \\
Demanda do cliente & $\mathrm{D}_{\mathrm{k}}$ & Parâmetro \\
Custo do transporte de biodiesel & $\alpha$ & Parâmetro \\
Avaliação obtida pelo fornecedor & $\mathrm{W}_{\mathrm{i}}$ & Parâmetro \\
Distância entre a usina e o cliente & $\mathrm{d}_{\mathrm{jk}}$ & Parâmetro \\
Quantidade transportada de biodiesel entre a usina e o cliente & $\mathrm{Y}_{\mathrm{jk}}$ & Variável de decisão \\
Valor de imposição do selo social & $\Delta$ & Parâmetro \\
\hline
\end{tabular}

Por último, constata-se a existência do elo que representa a demanda por biodiesel. Nesse caso, a demanda do cliente $k$ é ilustrada pelo parâmetro $D_{k}$. Existe ainda uma distância associada entre a usina $j$ e o cliente $\mathrm{k}\left(\mathrm{d}_{\mathrm{jk}}\right)$ e a quantidade transportada entre a usina j e o cliente $\mathrm{k}\left(\mathrm{y}_{\mathrm{jk}}\right)$. Por último, existe o custo de transporte entre esses dois elos como sendo $\alpha$, expresso por $\$ / 1 . \mathrm{km}$.

Com esse esquema preparado, foram elaborados dois modelos diferentes, o primeiro, sem levar em conta a restrição imposta pelo governo, através do selo social, e outro que a considera. Os dois modelos serão apresentados nos tópicos a seguir.

\subsection{Modelo sem a imposição do selo social}

O objetivo desse modelo é procurar uma solução para a minimização dos custos de transportes na cadeia principal de produção de biodiesel. A Equação 4 ilustra essa função, chamada de função objetivo (F0). Pela Equação 4, a função objetivo do problema é a minimização do custo e está associada às distâncias entre fornecedores e usinas e entre as usinas e os clientes. A essas distâncias estão associados um custo de transporte \$/L.km e a quantidade transportada entre cada fornecedor e a usina $\left(\mathrm{x}_{\mathrm{ij}}\right)$, e entre a usina e o cliente $\left(\mathrm{y}_{\mathrm{jk}}\right)$. 0 objetivo desse modelo é encontrar as relações de transporte que ofereçam o menor custo total de transporte entre os fornecedores, usinas e clientes.

$$
\begin{aligned}
& F O=\min \sum_{i} \sum_{j} X_{i j} \cdot d_{i j} \cdot \frac{\beta}{W_{i}}+\sum_{j} \sum_{k} Y_{j k} \cdot d_{j k} \cdot \alpha \\
& \sum_{j} X_{i j} \leq O_{i}, \forall_{i}
\end{aligned}
$$


$\sum_{i} X_{i j} \leq C_{j}, \forall \mathrm{j}$

$\sum_{k} Y_{j k} \leq \sum_{i} X_{i j}, \forall \mathrm{j}$

$\sum_{j} Y_{j k} \geq D_{k}, \forall \mathrm{k}$

$X_{i j} \geq 0 \quad$ e $\quad Y_{j k} \geq 0$

Porém, existem algumas restrições a serem obedecidas no modelo. A primeira restrição diz que o somatório da quantidade transportada de MP, oriunda de cada fornecedor i para todas as usinas, deve ser inferior ou igual à disponibilidade de MP do mesmo (Oi), conforme a Equação 5.

Outra restrição definida no modelo diz que a quantidade total transportada de MP dos fornecedores para a usina $\mathrm{j}$ deve ser igual ou inferior à sua capacidade produtiva ( $\mathrm{Cj}$ ). Isso foi adotado devido ao risco de oxidação que o óleo apresenta quando é armazenado, tornando-se inviável para a produção de biodiesel. A Equação 6 ilustra esse fato.

Em seguida, foram definidas algumas restrições na parte da cadeia entre as usinas e os clientes. A primeira se baseia no pressuposto de que uma quantidade $\mathrm{x}$ de óleo produz a mesma quantidade de biodiesel. lsso implica que o somatório da quantidade de biodiesel transportada de cada usina $\mathrm{j}$ para as diferentes demandas deve ser igual ou menor à quantidade de óleo vegetal transportada dos fornecedores para a respectiva usina $\mathrm{j}$, como ilustrado na Equação 7.

Foi definido ainda que o somatório da quantidade de biodiesel transportado das usinas para a demanda $\mathrm{k}$ deve ser maior ou igual a essa demanda. Essa restrição é ilustrada pela Equação 8.

Vale destacar as restrições que dizem respeito às quantidades transportadas entre os fornecedores e as usinas e entre as usinas e os clientes, que devem ser maiores ou iguais a zero, ilustradas nas restrições 9.

\subsection{Modelo com a imposição do selo social}

Para a formatação desse modelo, segundo essa nova restrição imposta, o selo social, a variável "X" foi desmembrada em duas variáveis: $X_{i 1 j}$ e $X_{i 2 j}$. Essa dissociação está relacionada com a política de governo, onde o fator 1 indica agricultura familiar, e o fator 2, outro tipo de negócio.

Do mesmo modo, o objetivo do modelo é o estabelecimento de uma estrutura de fornecimento e distribuição que vise um custo total mínimo na estrutura de transporte. Esse objetivo é ilustrado na Equação 10.

$F O=\min \sum_{j} \beta\left(\sum_{i 1} X_{i 1 j} \cdot \frac{d_{i 1 j}}{W_{i 1}}+\sum_{i 2} X_{i 2 j} \cdot \frac{d_{i 2 j}}{W_{i 2}}\right)+\sum_{j} \sum_{k} Y_{j k} \cdot d_{j k} \cdot \alpha \quad(10)$

$\sum_{j} X_{i 1 j} \leq O_{i 1}, \forall_{i 1}$

$\sum_{j} X_{i 2 j} \leq O_{i 2}, \forall_{i 2}$

$\sum_{i 1} X_{i 1 j}+\sum_{i 2} X_{i 2 j} \leq \sum_{j} C_{j}, \forall \mathrm{j}$

$\sum_{i 1} X_{i 1 j} \geq \Delta .\left(\sum_{i 1} X_{i 1 j}+\sum_{i 2} X_{i 2 j}\right), \forall_{j}$

$\sum_{k} Y_{j k} \leq \sum_{i 1} X_{i 1 j}+\sum_{i 2} X_{i 2 j}, \forall_{j}$

$\sum_{j} Y_{j k} \geq D_{k}, \forall_{k}$

$X_{i j} \geq 0$ e $Y_{j k} \geq 0$

Nesse caso, $W_{i 1}$ e $W_{i 2}$ são as avaliações obtidas pelos fornecedores. Analogamente ao modelo anterior, este está sujeito a algumas restrições. Inicialmente, o somatório da quantidade de MP, oriunda de agricultura familiar (AF) transportada de cada fornecedor para as usinas, deve ser menor/ igual à disponibilidade de MP da mesma, de acordo com a Equação 11.

Como para a MP oriunda da AF, segue a mesma restrição para a MP advinda de outros tipos de negócio. A Equação 12 retrata essa restrição.

A próxima restrição trabalha com o transporte de MP até a capacidade produtiva da usina, onde o somatório da quantidade de MP transportada (advinda da AF) e o somatório da quantidade de MP (advinda do agronegócio) entre os fornecedores e a usina j deve ser inferior à sua capacidade, pelos motivos já explicados, ilustrados na Equação 13. Pela imposição do governo quanto ao selo social, foi apresentada a Equação 14, em que pelo menos 30\% da MP comprada pelas usinas dos seus fornecedores devem ser oriundos da AF.

Por último, observa-se o grupo de restrições por parte da demanda, o que é caracterizado, analogamente, ao modelo anterior (Equações 15 e 16).

Vale destacar ainda as restrições que dizem que as quantidades transportadas entre os fornecedores e as usinas e entre as usinas e os clientes devem ser maiores ou iguais a zero, ilustrados nas restrições 17. 
Com a formulação matemática, a etapa seguinte consiste na implementação dessa modelagem, que foi feita no lingo 8.0. 0 próximo tópico descreve como essa etapa foi realizada.

Para a elaboração do modelo, considerou-se o custo de transporte de MP e biodiesel como sendo $\mathrm{R} \$ 0,0002825$ por litro por quilômetro. Esse dado foi considerado com base no modelo de custos fornecido pela TRC (ASSOCIAÇÃO..., 2009). Vale ressaltar que esses valores variam de acordo com a distância. Para fim de simplificação, adotou-se um valor médio para que fossem comparados os modelos sob a ótica de certificação e competitividade.

\section{Estudo de caso}

\subsection{Dados utilizados}

Para a avaliação do modelo proposto, foram pesquisados alguns dados de disponibilidade de MP, capacidade das usinas cearenses, distâncias envolvidas e uma estimativa de custos de transportes.

A Tabela 8 ilustra as disponibilidades de MP identificadas na região. Esses dados são hipotéticos, onde foram associados valores de oferta de MP dos maiores produtores de MP do estado do Ceará.

Para a Tabela 8, observa-se que o agronegócio possui uma capacidade de fornecimento de $58 \%$ de toda a MP disponível, e a agricultura familiar um potencial de fornecimento de $42 \%$ da oferta.

Para a composição do modelo, utilizaram-se as capacidades produtivas das usinas no estado do Ceará para visualizar a eficácia do modelo proposto. A Tabela 9 ilustra as capacidades adotadas. Pressupõe-se, nesse caso, que as demandas das usinas são atendidas pela oferta de MP.
Fazendo uma associação da capacidade produtiva das usinas com a disponibilidade de MP, observa-se que a agricultura familiar possui capacidade de fornecimento para as usinas que supre $61,45 \%$ da demanda das usinas, e o agronegócio tem capacidade de fornecer $83,80 \%$ da capacidade estimada das usinas estudadas. Assim, o modelo proposto encontra solução viável apenas para uma quantidade máxima de MP da agricultura familiar e de agronegócio, exposto acima.

As distâncias dos fornecedores para as usinas são reais (Tabela 10), entre os maiores produtores de mamona do estado (municípios) e as usinas produtoras do estado.

Observa-se que, em sua maioria, pode-se considerar que a produção de mamona no estado é advinda da agricultura familiar. Para a avaliação do modelo, porém, foi adotado que algumas dessas produções eram referentes à agricultura familiar e, outras, ao agronegócio.

A Tabela 11 traz as demandas utilizadas. Porém, a demanda futura por biodiesel tende a ser mais fragmentada e não concentrada nas distribuidoras de combustível.

Essas distâncias foram utilizadas devido à demanda futura por biodiesel tender a se fragmentar e não estar somente atrelada às distribuidoras de diesel. Essa determinação se justifica também por não ser o foco do modelo a distribuição, mas, sim, a parte de suprimentos. A Tabela 12 ilustra essa matriz.

Esses dados foram utilizados para a elaboração dos cenários estudados, avaliando os impactos dessas medidas no custo de transporte na cadeia de suprimentos. A Tabela 13 ilustra as características dos cenários.

0 primeiro cenário elaborado trata da situação mais simples. Nesse caso, não foi levada em consideração nenhuma imposição sob os aspectos

Tabela 8. Capacidade de fornecimento de MP (litro).

\begin{tabular}{cccccc}
\hline Fornecedor & $\begin{array}{c}\text { Município } \\
\text { localizado }\end{array}$ & $\begin{array}{c}\text { Capacidade de } \\
\text { fornecimento } \\
\left(\times 10^{7}\right)\end{array}$ & Tipo de negócio & $\begin{array}{c}\text { AF } \\
\left(\times 10^{7}\right)\end{array}$ & $\begin{array}{c}\text { Agro } \\
\left(\times 10^{7}\right)\end{array}$ \\
\hline 1 & Boa Viagem & 1 & AF & 1 & 0 \\
2 & ltatira & 5 & AGRO & 0 & 5 \\
3 & Parambu & 2 & AF & 2 & 0 \\
4 & Pedra Branca & 3 & AGRO & 0 & 3 \\
5 & Crateús & 2 & AF & 2 & 0 \\
6 & Canindé & 1 & AGRO & 0 & 0 \\
7 & Mauriti & 4 & AF & 5 & 4 \\
8 & Catunda & 5 & AGRO & 0 & 0 \\
9 & Tauá & 1 & AGRO & 0 & 1 \\
10 & Independência & 2 & & 11 & 2 \\
\hline
\end{tabular}


Tabela 9. Capacidade produtiva hipotética.

\begin{tabular}{cc}
\hline Usina & Capacidade produtiva (1) $\left(\times 10^{6}\right)$ \\
\hline 1 & 57 \\
2 & 108 \\
3 & 7 \\
4 & 7 \\
\hline Total & 179 \\
\hline
\end{tabular}

Tabela 10. Matriz de distâncias (km).

\begin{tabular}{crrrr}
\hline \multirow{2}{*}{$\begin{array}{c}\text { Fornecedor } / \\
\text { usina }(\mathrm{km})\end{array}$} & \multicolumn{4}{c}{ Usina } \\
\cline { 2 - 5 } & 1 & \multicolumn{1}{c}{2} & \multicolumn{1}{c}{3} & \multicolumn{1}{c}{4} \\
\hline 1 & 132,4 & 143,2 & 123,1 & 119,0 \\
2 & 227,2 & 144,6 & 217,9 & 213,8 \\
3 & 201,1 & 296,2 & 64,1 & 194,1 \\
4 & 113,0 & 129,1 & 103,7 & 79,0 \\
5 & 120,0 & 242,1 & 137,0 & 192,0 \\
6 & 233,8 & 98,0 & 224,5 & 220,4 \\
7 & 431,7 & 407,7 & 369,7 & 275,7 \\
8 & 95,0 & 251,0 & 232,0 & 287,0 \\
9 & 137,0 & 232,1 & 130,0 & 130,0 \\
10 & 45,0 & 197,1 & 111,7 & 147,0 \\
\hline
\end{tabular}

Tabela 11. Demandas hipotéticas (litros).

\begin{tabular}{cc}
\hline Ponto de demanda & Valor de demanda $\left(\times 10^{7}\right)$ \\
\hline 1 & 3 \\
2 & 27 \\
3 & 14 \\
4 & 18 \\
5 & 45 \\
6 & 45 \\
\hline Total & 179 \\
\hline
\end{tabular}

Tabela 12. Distâncias hipotéticas (km).

\begin{tabular}{cccccrc}
\hline \multirow{2}{*}{$\begin{array}{c}\text { Usina / Ponto } \\
\text { de demanda }\end{array}$} & $\mathbf{1}$ & 2 & 3 & \multicolumn{1}{c}{ Demanda } & \multicolumn{1}{c}{5} & 6 \\
\cline { 2 - 7 } & 200 & 500 & 300 & 400 & 600 & 100 \\
2 & 200 & 150 & 350 & 100 & 50 & 130 \\
3 & 300 & 500 & 200 & 30 & 50 & 200 \\
4 & 100 & 500 & 600 & 1000 & 200 & 300 \\
\hline
\end{tabular}

de sustentabilidade e competitividade (parâmetro $W_{\mathrm{i}}$ ), nem a imposição do selo social (parâmetro $\Delta$ ).

Logo, a empresa pode comprar de quem quiser, sem nenhuma restrição. 0 único objetivo, nesse caso, é a obtenção do menor custo possível.

0 segundo cenário considera a imposição dos critérios de certificação e competitividade. Nesse segundo cenário também não foram consideradas as imposições do selo social. Observou-se que a adoção do modelo de avaliação representou uma mudança nos custos.
Tabela 13. Cenários propostos.

\begin{tabular}{|c|c|c|}
\hline $\begin{array}{l}\text { Cenário } \\
\text { proposto }\end{array}$ & $\begin{array}{l}\text { Adoção de } \\
\text { selo social }\end{array}$ & $\begin{array}{c}\text { Presença da avaliação } \\
\text { dos fornecedores }\end{array}$ \\
\hline 1 & Sem selo social & $\begin{array}{l}\text { Sem avaliação dos } \\
\text { fornecedores }\end{array}$ \\
\hline 2 & Sem selo social & $\begin{array}{l}\text { Com avaliação dos } \\
\text { fornecedores }\end{array}$ \\
\hline 3 & Com selo social (30\%) & $\begin{array}{l}\text { Sem avaliação dos } \\
\text { fornecedores }\end{array}$ \\
\hline 4 & Com selo social (30\%) & $\begin{array}{l}\text { Com avaliação dos } \\
\text { fornecedores }\end{array}$ \\
\hline 5 & Com selo social (40\%) & $\begin{array}{l}\text { Sem avaliação dos } \\
\text { fornecedores }\end{array}$ \\
\hline 6 & Com selo social (40\%) & $\begin{array}{l}\text { Com avaliação dos } \\
\text { fornecedores }\end{array}$ \\
\hline
\end{tabular}

No terceiro cenário, o modelo englobou a imposição governamental do selo social (30\% da MP advinda da agricultura familiar). Porém, não foram adotados os critérios de certificação e competitividade na cadeia.

0 quarto cenário engloba a imposição governamental do selo social e os critérios de certificação e competitividade. Nesse caso, também foi adotado o mesmo valor para o selo social $(\Delta=30 \%)$.

0 quinto cenário contempla um maior percentual de MP advinda da agricultura familiar $(\Delta=40 \%)$, porém desconsidera os critérios de certificação e competitividade.

Por último, existe o cenário seis, que contempla os critérios de certificação e competitividade e adota o valor de $40 \%$ para o selo social. Para este, a mudança no custo já foi bem mais significativa.

Se a hipótese de fornecimento fosse que a MP oriunda da AF fosse superior a 61,45\%, significaria que o modelo se tornaria inviável pela falta de disponibilidade de MP, dado que a quantidade de MP só é capaz de atender ao percentual estipulado. Assim, antes de rodar esse modelo, é necessário avaliar qual o potencial de fornecimento de MP tanto da $\mathrm{AF}$, como do agronegócio.

\section{Análise dos resultados}

Essa etapa do trabalho busca fazer uma comparação entre os cenários propostos. A Figura 6 ilustra o desempenho dos custos pela comparação dos cenários. Constata-se que os custos obtidos, quando se impõe o modelo de avaliação de fornecedores, tende a ser maior que o custo obtido quando se coloca a imposição governamental do selo social. 


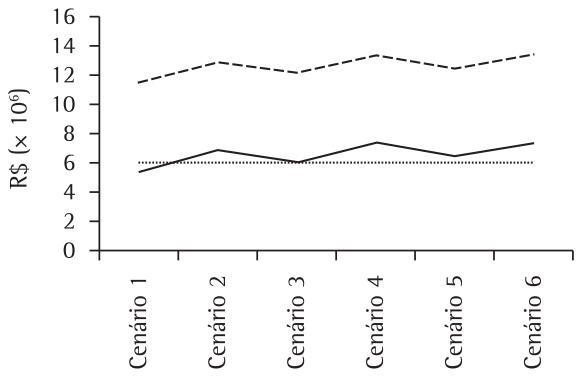

- Suprimento ……... Distribuição --- Total dos custos

Figura 6. Comparação entre os cenários.

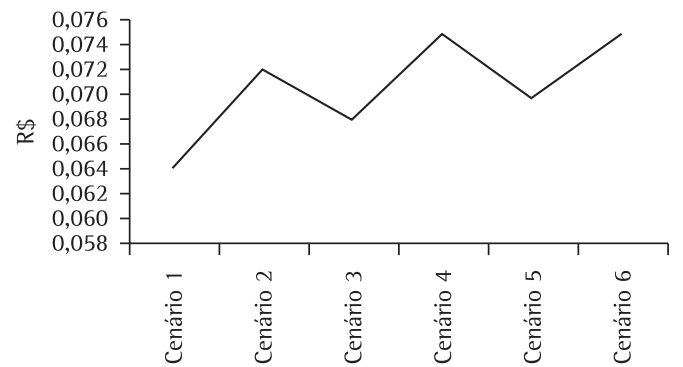

Figura 7. Custo do transporte por litro de biodiesel.

Tabela 14. Incremento no custo entre cenários.

\begin{tabular}{ccccccr}
\hline Matriz de & \multicolumn{7}{c}{ Cenário (\%) } \\
\cline { 2 - 7 } incrementos & $\mathbf{1}$ & 2 & \multicolumn{1}{c}{3} & \multicolumn{1}{c}{4} & \multicolumn{1}{c}{5} & \multicolumn{1}{c}{6} \\
\hline Cenário 1 & - & 12,45 & 6,05 & 16,77 & 8,86 & 16,79 \\
Cenário 2 & - & - & $-5,69$ & 3,83 & $-3,20$ & 3,86 \\
Cenário 3 & - & - & - & 10,10 & 2,64 & 10,13 \\
Cenário 4 & - & - & - & - & $-6,77$ & 0,02 \\
\hline
\end{tabular}

A próxima etapa avalia a diferença entre os custos de cada cenário. A Tabela 14 apresenta a matriz com os incrementos nos custos oriundos de cada modelo.

Avaliando o cenário 1, o mais simples, observa-se que o mesmo é o que apresenta o menor custo. Quando o modelo de avaliação de fornecedores é acrescido (cenário 2), nota-se um incremento no custo na ordem de $12,45 \%$. Por outro lado, partindo-se do cenário 1 para o cenário 3 (que engloba somente a restrição do selo social - $\Delta$ ) constata-se que o incremento nos custos é menos da metade do incremento causado pelo modelo de avaliação. Com isso, pode-se constatar que o custo oriundo do modelo de seleção é maior que o custo da imposição do selo social.

Partindo para a análise do cenário 2, em comparação com os demais, pode-se observar que o modelo de seleção de fornecedores apresenta custo maior que as imposições de selo social dos cenários 3 e 5, que apresentaram uma redução de 5,69 e 3,20\%, respectivamente.

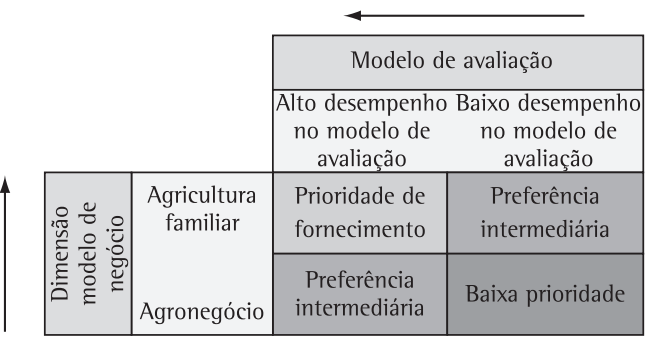

Figura 8. Priorização de fornecimento.

Tabela 15. Percentual de fornecimento de MP por usina por cenário.

\begin{tabular}{|c|c|c|c|c|c|c|}
\hline Cenário 3 & Usina & Total $\left(\times 10^{6}\right)$ & $\mathrm{AF}\left(\times 10^{5}\right)$ & $\operatorname{Agro}\left(\times 10^{5}\right)$ & $\% \mathrm{AF}$ & $\%$ Agro \\
\hline \multirow{4}{*}{$\begin{array}{c}\text { Com selo (30\%) } \\
\text { sem av }\end{array}$} & 1 & 57 & 370 & 200 & 65 & 35 \\
\hline & 2 & 108 & 324 & 756 & 30 & 70 \\
\hline & 3 & 7 & 70 & 0 & 100 & 0 \\
\hline & 4 & 7 & 21 & 49 & 30 & 70 \\
\hline Cenário 5 & Usina & Total & $\mathrm{AF}$ & Agro & $\% \mathrm{AF}$ & \% Agro \\
\hline \multirow{4}{*}{$\begin{array}{c}\text { Com selo (40\%) } \\
\text { sem av }\end{array}$} & 1 & 57 & 370 & 200 & 65 & 35 \\
\hline & 2 & 108 & 432 & 648 & 40 & 60 \\
\hline & 3 & 7 & 70 & 0 & 100 & 0 \\
\hline & 4 & 7 & 28 & 42 & 40 & 60 \\
\hline Cenário 4 & Usina & Total & $\mathrm{AF}$ & Agro & $\% \mathrm{AF}$ & $\%$ Agro \\
\hline \multirow{4}{*}{$\begin{array}{c}\text { Com selo (30\%) } \\
\text { com av }\end{array}$} & 1 & 57 & 500 & 70 & 88 & 12 \\
\hline & 2 & 108 & 409 & 671 & 38 & 62 \\
\hline & 3 & 7 & 70 & 0 & 100 & 0 \\
\hline & 4 & 7 & 21 & 49 & 30 & 70 \\
\hline Cenário 6 & Usina & Total & $\mathrm{AF}$ & Agro & $\% \mathrm{AF}$ & $\%$ Agro \\
\hline \multirow{4}{*}{$\begin{array}{c}\text { Com selo }(40 \%) \\
\text { com av }\end{array}$} & 1 & 57 & 470 & 100 & 82 & 18 \\
\hline & 2 & 108 & 432 & 648 & 40 & 60 \\
\hline & 3 & 7 & 70 & 0 & 100 & 0 \\
\hline & 4 & 7 & 28 & 42 & 40 & 60 \\
\hline
\end{tabular}


Comparando-se o cenário 3 com os demais (em especial com os cenários 4 e 5), pôde-se observar que o incremento dos custos, quando o modelo de avaliação é incorporado (cenário 4) juntamente com a imposição do selo social, é um pouco menor que o aumento causado quando o selo social não é adotado (cenário $1 \times$ cenário 2). Assim, o modelo de avaliação de fornecedores tem um impacto na ordem de 11\%, em média, para o modelo apresentado.

Em uma análise de todos os cenários propostos, o que obteve pior desempenho, do ponto de vista de custo, foi o cenário 6 , selo social de $40 \%$, com modelo de avaliação de fornecedores. Isso ilustra que, à medida que vão se impondo restrições ao sistema analisado, maior o custo envolvido. A tendência normal é aumentar os custos à medida que se incorpora o maior valor para o selo social. A Figura 7 ilustra o impacto do custo de transporte no litro de biodiesel vendido. Para a construção desse gráfico, levou-se em consideração o valor total de transportes (suprimentos + distribuição) e dividiu-se pela quantidade total de biodiesel transportado, obtendo-se um custo de transporte por litro.

Diversos jornais noticiam que o preço do biodiesel varia em torno de R\$2.36 (AGÊNCIA..., 2009) por litro para a distribuidora. Levando em consideração esses valores, pode-se observar que o custo de transporte tem um impacto reduzido nesse preço, algo inferior a 5\%. Assim, pode-se observar que a utilização de critérios de certificação e competitividade não possui impactos significativos nos custos de transportes. A grande preocupação é garantir o fornecimento de MP por parte dos produtores, atual gargalo constatado no sistema.

\section{Considerações finais}

0 grande objetivo do modelo desenvolvido é priorizar o fornecimento de matéria-prima oriunda da agricultura familiar. Porém, é necessário que sejam atendidos os critérios de sustentabilidade socioambiental e de competitividade. A Figura 8 mostra que a prioridade de fornecimento se dá em função de duas características básicas: se o fornecimento é proveniente de agricultura familiar ou agronegócio e se o fornecedor teve avaliação superior ou inferior em relação aos demais. 0 primeiro quadrante ilustra a melhor situação de fornecimento para o produtor, onde ele é do tipo $\mathrm{AF}$ e tem uma boa avaliação em relação aos demais. 0 quadrante direito superior ilustra o AF com baixa avaliação, considerado como segunda prioridade até o atendimento da restrição do selo social. Depois desse ponto, o que tiver a avaliação global superior será o fornecedor (entre os localizados nesse quadrante e o inferior esquerdo). Por último, existem os fornecedores oriundos de agronegócio que possuem baixa avaliação. Nesse caso, a prioridade de fornecimento é a última.

lsso significa que o modelo de seleção de fornecedores apresenta um impacto forte que, nesse caso, os agricultores familiares possuem melhor avaliação, o que, comparando o cenário 3 com o cenário 4, implica num maior fornecimento da $\mathrm{AF}$.

Analogamente, quando se passa do cenário 5 para o cenário 6 , a quantidade de MP oriunda da $\mathrm{AF}$ tende a aumentar devido à melhor avaliação do tipo de negócio. Esses fatos podem ser constatados na Tabela 15.

Assim, investir na melhoria dos indicadores da agricultura familiar pode representar uma melhoria na competitividade destes. Logo, esse trabalho propõe uma nova forma de pensar o selo social, em que a prioridade passa a ser capacitar o agronegócio familiar para torná-lo competitivo. Isso significa real melhoria na qualidade de vida e distribuição de renda, ao contrário do selo social como existe hoje, que trata de uma política mais assistencialista que não provoca o pequeno agricultor a se desenvolver e competir no mercado globalizado.

\section{Referências}

AGENNCIA NACIONAL DO PETRÓLEO - ANP. Disponível em: www.anp.gov.br. Acesso em: 30 nov. 2008.

ARENALES, M. et al. Pesquisa Operacional para cursos de engenharia. Rio de Janeiro: Elsevier, 2007.

ASSOCIAÇÃO NACIONAL DO TRANSPORTE DE CARGA E LOGÍSTICA - TRC. Tabelas referenciais de custos do TRC. 2009. CD ROM.

CAIXETA-FILHO, J. V. Pesquisa Operacional: técnicas de otimização aplicados a sistemas agroindustriais. São Paulo: Atlas, 2004

CARMO, B. B. T. Identificação das demandas e ofertas tecnológicas na cadeia produtiva do biodiesel no estado do Ceará. Monografia (Conclusão de Curso em Engenharia de Produção Mecânica)-Universidade Federal do Ceará, Fortaleza, Ceará, Brasil, 2007.

CARMO, B. B. T. Proposta de modelo para seleção de fornecedores e otimização do transporte na cadeia produtiva do biodiesel com base em critérios de sustentabilidade. Dissertação (Mestrado em Engenharia de Transportes)-Universidade Federal do Ceará, Fortaleza, Ceará, Brasil, 2009.

CAVALCANTI, R. C. Sistema multicritério para apoiar a compra de imóveis urbanos multifamiliares do mercado imobiliário recifense baseado no método SMARTS. Dissertação (Mestrado)-Programa de Pós-graduação em Engenharia de Produção, Universidade Federal de Pernambuco - UFPE, Recife, 2007.

CHEN, Y.; KILGOUR, D. M. E.; HIPEL, K. W. An integrated approach to multiple criteria decision aid: consequencebased preference aggregation. Disponivel em: http:// www.eng.uwaterloo.ca/ y3chen/Papers/MCDA\%20 2004.pdf. Acesso em: 15 abr. 2009. 
EDWARDS, W.; BARRON, F. H. SMARTS and SMARTER: Improved Simple Methods for Multiattribute Utility Measurement. Organizational Behavior and Human Decision Processes, v. 60, p. 306-325, 1994.

HAMMOND, J. S.; KENNEY, R. L.; RAIFFA, H. Smart Choices A Practical Guide to Making Better Decisions. Boston: Harvard Business School Press, 1999.

HOLANDA, F. A. Biodiesel e inclusão social. Brasília, 2006.

KEENEY, R. L.; RAIFFA, H. Decision with multiple objectives: preferences and value tradeoffs. [S.1.]: John Wiley \& Sons, 1976.
KUJAWSKI, E. Multi-Criteria Decision Analysis: limitations, pitfalls, and practical difficulties. Disponivel em: http:// www.osti.gov/bridge/servlets/purl/813572-z2LVXu/ native/813572.pdf. Acesso em: 15 abr. 2009.

LOPES, Y. G.; ALMEIDA, A. T. Enfoque multicritério para a localização de instalações de serviço: aplicação do método SMARTER. Revista Sistemas \& Gestão, v. 3, p.114-128, 2008.

PARREIRAS, R. 0. Algoritmos Evolucionários e Técnicas de Tomada de Decisão em Análise Multicritério. Tese (Doutorado)-Universidade Federal de Minas Gerais, Belo Horizonte, 2006.

\title{
Suppliers selection model and its transportation cost impacts
}

\begin{abstract}
Nowadays, there is a world demand for renewable energies. These kinds of energy must be sustainable to be considered renewable. The consumption of diesel has increased and so has the emission of greenhouse gases. Bio-diesel is an alternative to reduce this kind of emission. But, when the matter is bio-diesel, there are some challenges to be overcome. This first one is that this chain must be competitive. There are some criteria to evaluate the competitiveness of chains. Also, it is known that Brazil has a big potential to export this kind of fuel. However, some countries are developing norms to evaluate whether this fuel is sustainable and whether it has positive impacts in society. The present work creates a model to evaluate bio-diesel chain suppliers using competitiveness and certification criteria identified in this chain. Smarter methodology was used in order to do so. This model was put together along with a transport optimization model. It could be observed that the "selo social" has an important impact in transportation costs. When we analyzed competitiveness and certification evaluation models, we could observe that these suppliers evaluation model changes this relationship.
\end{abstract}

\section{Keywords}

Bio-diesel. Suppliers selection model. Competitiveness. Sustainability. 